\title{
Original Article (short paper) \\ Estimate of Resting Energy Expenditure by DXA in Boys of Different Nutritional Statuses
}

\author{
Ana Claudia Rossini Venturini ${ }^{1 *}$, Pedro P. Abdalla ${ }^{1}$, André Pereira dos Santos $^{1}$, Franciane Goes Borges ${ }^{1}$, \\ Thiago Cândido Alves ${ }^{1}$, Dalmo R. L. Machado ${ }^{1}$ \\ ${ }^{1}$ Universidade de São Paulo, USP, Ribeirão Preto, SP, Brazil
}

\begin{abstract}
Aim: to estimate the resting energy expenditure (REE) of organ tissue components using Dual Energy x-ray Absorptiometry (DXA) in pubertal boys. The mass of components and REE were compared among groups of different nutritional statuses. Methods: a sample of 278 boys (13.7 \pm 2.4 years old) was grouped according to BMI nutritional status for Brazilian children and adolescents ${ }^{1}$ such as Underweight (UW), Normal weight (NW), Overweight $(\mathrm{OW})$, and Obese (OB). The REE of organ tissue components given by DXA was calculated using specific models for skeletal muscle tissue (SMT), adipose tissue (AT), bone tissue (BT) and residual tissue (RT) based on previous reports. The absolute and relative REE ( $\mathrm{REE}_{\mathrm{DXA}}$ ) of each component were statistically compared among groups. Results: No differences of total $\mathrm{REE}_{\mathrm{DXA}}$ were found among nutritional groups $\left(F_{(3,274)}=0.071, p=0.976\right)$. When, however, specific REE was considered per component, differences were found for BT and $\mathrm{REE}_{\mathrm{BT}}$ between NW-OW $(p=0.003)$ and NW$\mathrm{OB}(p=0.048)$; in AT and $\mathrm{REE}_{\mathrm{AT}}$ for all the groups $(p<0.001)$, except between UW-NW ( $\left.p=1.000\right)$; in RT and $\mathrm{REE}_{\mathrm{RT}}$ between NW-OB $(p=0,022)$ and SMT and $\operatorname{REE}_{\mathrm{SMT}}(p=0,039)$. Greater proportions of organ tissue of RT and high metabolic rates, were observed in the UW group (78.3\%) in comparison to the OB group (60.7\%). Conclusion: This approach provides a new opportunity to examine energy metabolism for individual differences of pediatric populations. It is an applicable strategy both to prescribe exercises and to administer diets to this population, as it reveals the magnitude of heat-producing body components.
\end{abstract}

Keywords: body composition, energy expenditure, anthropometry, adolescents, children.

\section{Introduction}

Conventional equations used to estimate resting energy expenditure (REE) consider generalized body dimensions without taking into account the different metabolic activities of tissues and organs ${ }^{2}$. Hence, adjusting REE for different body components is essential to making intra-individual comparisons ${ }^{3,4}$. Fat free mass (FFM) is considered the best predictor of $\mathrm{REE}^{5}$, because it consists of organs with a high metabolic rate such as the heart, spleen, kidneys, brain, liver, gastrointestinal tract ${ }^{6}$ and large tissue structures (skeletal muscle, and osteoarticular systems and ligaments). Therefore, both anatomically and metabolically, FFM is a heterogeneous compartment ${ }^{3,4}$, the specific metabolic rate of which can be measured, for instance, by the difference of arteriovenous concentration of tissues and blood flow ${ }^{3}$. The procedures to make such estimates involve various assumptions ${ }^{7}$ still seldom reported in the literature. Research, however, has advanced understanding concerning the relationship between estimated metabolic rate and body composition (BC) to predict the REE of each component ${ }^{8}$.

Intra-individual REE differences can be explored using predictive models at a tissue level ${ }^{3,9,10}$, with an approach that enables associating the variation of metabolic rate among individuals that is explained by $\mathrm{BC}^{11}$. To do this, the individual mass of an organ or tissue is determined using image analysis techniques, multiplied by a specific metabolic rate ${ }^{3}$. That was the way Hayes, Chustek, Wang, Gallagher, Heshka, Spungen ${ }^{12}$ confirmed the hypothesis that REE can be estimated using five components measured by DXA: brain area, appendicular lean soft tissue (ALST), bone mineral content (BMC), total fat mass, and body weight. REE can also be estimated using other configurations, such as Usui, Taguchi, Ishikawa-Takata and Higuchi $^{6}$ did when measuring four organ tissue components: adipose tissue (AT), bone tissue (BT), skeletal muscle tissue (SMT), and residual tissue (RT), which corresponds to the difference between body mass and the total of the remaining. This last model sounds more promising, as it considers the high metabolic rate $(54 \mathrm{kcal} / \mathrm{kg} / \mathrm{d})$ of organs ${ }^{6}$ as part of the RT.

So, DXA can be considered accurate for determining $\mathrm{BC}$ at the 3-C model, as it includes components at a molecular level ${ }^{13}$ : fat mass (FM), BMC, and ALST from a whole-body scan ${ }^{14}$. DXA presents the lowest operational cost and low risk, as well, when compared to computed tomography and magnetic resonance ${ }^{15}$, which makes the method highly recommended for pediatric populations. Studies stress the use of DXA to provide a "metabolic map" that is able to precisely correct REE variation among individuals ${ }^{12}$, in addition to differentiating energy expenditure between high and low metabolic rate tissues.

According to these estimates, individuals with a larger body mass present higher REE compared to people with lower weight. It is, however, a mistake, to consider only body mass as a normative parameter of REE. The greater body mass 
of obese individuals is mostly composed of fat, an inertial metabolic component with a specific expenditure rate, i.e., energy expenditure by unit of body weight is also low ${ }^{16}$.

Hence, information regarding nutritional status and its relationship with REE needs to be better understood, while the mechanisms associated with greater energy demands and the physiological basis of this process need to be clarified ${ }^{17}$ to consider specific and individual metabolism. For this reason, it seems desireable to consider nutritional status to accurately determine every REE. Additionally, the rate of energy production per unit of metabolically active tissue is not constant; it varies according to body size ${ }^{9}$. These relationships provide new insights in the field of energy metabolism, favoring greater understanding of the relationships inherent to $\mathrm{BC}$ and $\mathrm{REE}^{18}$.

The most intense transformations in human growth take place during childhood and adolescence. The functional evolution of body systems and structures occurs at very distinct interindividual speeds and periods ${ }^{14}$, based on changes that take place in cells, tissues, and various body systems and compartments ${ }^{19}$. Energy expenditure during growth includes energy spent on tissue functioning and additional energy used to synthesize new tissues ${ }^{20}$. Estimates of REE attributed to physical growth reach $20 \%{ }^{21}$, though more specific estimates consider a daily expenditure for each age and sex. An energy cost of $2 \mathrm{kcal} / \mathrm{g}$ of body weight gain for growth is an acceptable parameter of such an estimate ${ }^{17}$. When considering the potential variation of $\mathrm{BC}$ among children and adolescents of the same age and sex, the classification of nutritional status with adequately estimated REE is essential to diagnosing nutritional differences ${ }^{1}$. Currently, studies have concentrated on the adult population, while the use of this model in the pediatric population has been ignored.

Therefore, the challenge of determining the specific expenditure of body components remains, as well as that of confirming the effectiveness of DXA in estimating the interindividual REE of children and adolescents. Given the previous discussion, this study's purposes were: a) to determine the REE of each component based on the 3-C model given by DXA, transformed to the tissue level of pubertal boys; and b) to compare the REE of different groups according to nutritional status, determining the specific mass and REE equivalent for each component.

\section{Method}

\section{Participants}

The sample of this cross-sectional study included 278 boys (11-16 years old) recruited in community sport centers and schools located in Presidente Prudente, SP, Brazil. Previous analyses did not present interracial differences or sports modalities $^{22}$, so the sample was considered homogeneous. The sample was composed of individuals who reported being Caucasians $(n=184)$, Afro-descendants $(n=56)$, Hispanics $(n=35)$, and Asians $(n=3)$. The individuals were invited to voluntarily participate in the study and did not present any pathology or medical restrictions, amputated body parts, nor did they take medications or undergo any clinical treatment that could affect metabolism or growth, and in pubertal Tanner ${ }^{23}$. Parents or legal guardians signed consent forms and the study was conducted in accordance with the guidelines and standards regulating research involving human subjects (Resolution $\mathrm{n}^{\circ}$. 466/12 from the National Council of Health), and was approved by the Institutional Review Board at the University of São Paulo, Ribeirao Preto School of Physical Education and Sport (CEP332007/EEFE/04.04.2007-2006/32).

\section{Procedures}

BMI $\left(\mathrm{kg} / \mathrm{cm}^{2}\right)$ was calculated in order to compare REE among the participants and classify nutritional status by age, that is: Underweight (UW), Normal Weight (NW), Overweight $(\mathrm{OW})$ and Obese $(\mathrm{OB})^{1}$. Body mass and height were measured according to the recommended method found in the literature ${ }^{24}$.

Body composition was estimated by scanning the whole body and portions of the body (Lunar DPX-NT - GE Medical, Software Lunar DPX encore 2007 version 11.40.004, Madison, WI). The exam provided total and regional components of: Total mass (g); FM (g); Lean soft tissue (g) (LST); BMC (g), and scanning area $\left(\mathrm{cm}^{2}\right)$. In order to calculate REE, the components measured by DXA (molecular level) were transformed at the organ-tissue level ${ }^{13}$, according to the previous equations, presented in Table 1.

Table 1. Transformation of components measured by DXA from the molecular level to the organ-tissue level and specific energy expenditure of each component (References in superscript).

\begin{tabular}{lll}
\hline \multicolumn{1}{c}{ Tissue } & \multicolumn{1}{c}{ Molecular Level $(\mathbf{k g})$} & \multicolumn{1}{c}{ Energy expenditure (kcal/d) } \\
\hline${ }^{41} \mathrm{AT}$ & $1.18(\mathrm{FM})$ & ${ }^{3,41} \mathrm{EE}_{\mathrm{AT}}=4.5(\mathrm{AT})$ \\
${ }^{42,43} \mathrm{BT}$ & $1.85(\mathrm{BMC}) \times 1.0436$ & ${ }^{3,41} \mathrm{EE}_{\mathrm{BT}}=2.3(\mathrm{BT})$ \\
${ }^{26} \mathrm{SMT}$ & $1.003(\mathrm{ALST})+0.039(\mathrm{BW})-1.315$ & ${ }^{3,41} \mathrm{EE}_{\mathrm{SMT}}=13(\mathrm{SMT})$ \\
$\mathrm{RT}$ & $\mathrm{BW}-(\mathrm{AT}+\mathrm{BT}+\mathrm{SMT})$ & ${ }^{3,41} \mathrm{EE}_{\mathrm{RT}}=54(\mathrm{RT})$ \\
Total & $\mathrm{BW}=(\mathrm{AT}+\mathrm{BT}+\mathrm{SMT}+\mathrm{RT})$ & $\mathrm{REE}_{\mathrm{DXA}}=\mathrm{EE}_{\mathrm{AT}}+\mathrm{EE}_{\mathrm{BT}}+\mathrm{EE}_{\mathrm{SMT}}+\mathrm{EE}_{\mathrm{RT}}$ \\
\hline
\end{tabular}

DXA: dual energy X-ray absorptiometry; AT: adipose tissue ( $\mathrm{kg}$ ); BT: bone tissue (kg); SMT: skeletal muscle tissue; RT: residual tissue (kg); FM: fat mass (kg); BMC: bone mineral content (kg); ALST: appendicular lean soft tissue (kg); BW: Body weight; EE: energy expenditure; $\mathrm{REE}_{\mathrm{DXA}}$ : resting energy expenditure given by DXA. 
All the youngsters were classified into maturational periods 2, 3 and 4 of pubic hair, and were considered pubertal ${ }^{23}$.

The approach used in this study to estimate total $\mathrm{REE}_{\mathrm{DXA}}$ was adapted from the model used by Usui, Taguchi, Ishikawa-Takata and Higuchi ${ }^{6}$ shared in four components, at the organ-tissue level derived from the DXA. The adaptation of the proposed model ${ }^{6}$ involved the replacement of adult SMT values ${ }^{25}$, for pediatric SMT values ${ }^{26}$, here called $\mathrm{REE}_{\mathrm{DXA}}$. The main reason for the pediatric adaptation of the model was the fast SMT growth and development, where major structural changes occur, including the relationships between height and length of legs and $\operatorname{arms}^{27}$.

\section{Statistical Analysis}

The descriptive statistics represented the values of central measures between groups of nutritional status. ANOVA (OneWay) was used to compare the groups' means (Underweight,
Normal Weight, Overweight, and Obese). Bonferroni's post hoc test was used when $p<0.05$. All analyses were conducted using SPSS version 23.0 (SPSS Inc., Chicago, IL) with the level of significance established at $\alpha=0.05$.

\section{Results}

The means concerning the descriptive characteristics, the $\mathrm{BC}$ at organ-tissue level, and REE of each component estimated by DXA of the total sample (and according to nutritional classification) are presented in Table 2 . The results concerning the groups' nutritional status reveal that most individuals $(73.38 \%)$ were classified as NW; $19.42 \%$ as $\mathrm{OW} ; 5.40 \%$ as $\mathrm{OB}$; and $1.80 \%$ as UW. Transformation of body components from the molecular level (DXA 3-C) to the organ-tissue level ${ }^{13}$ enabled calculation of the total $\mathrm{REE}_{\mathrm{DXA}}$, mass, and REE of each component.

Table 2: Descriptive statistics and Analysis of Variance of body composition and resting energy expenditure of boys classified according to their nutritional statuses.

\begin{tabular}{|c|c|c|c|c|c|}
\hline & Total $(n=278)$ & ${ }^{\mathrm{a}}$ Underweight $(\mathrm{n}=\mathbf{0 5})$ & ${ }^{b}$ Normal weight $(n=204)$ & 'Overweight $(n=54)$ & ${ }^{d}$ Obese $(n=15)$ \\
\hline Age (years) & $13.8(2.5)$ & $16.0(2.1)$ & $13.7(2.4)$ & $13.9(2.7)$ & $13.4(2.3)$ \\
\hline Height $(\mathrm{cm})$ & $161.2(14.7)$ & $175.9(17.1)$ & $160.7(14.9)$ & $161.6(13.8)$ & $160.5(13.3)$ \\
\hline Body weight (kg) & $52.4(15.9)$ & $46.1(8.0)^{\mathrm{d}}$ & $48.0(12.9)^{\mathrm{c}, \mathrm{d}}$ & $62.4(14.6)^{\mathrm{d}}$ & $79.0(17.5)$ \\
\hline $\mathrm{REE}_{\mathrm{DXA}}(\mathrm{kcal} /$ day $)$ & $1200.4(311.1)$ & $1259.7(212.9)$ & $1197.6(309.4)$ & $1205.7(339.2)$ & $1199.1(277.2)$ \\
\hline \multicolumn{6}{|c|}{ Body composition - organ-tissue level } \\
\hline BT (kg) & $4.1(1.3)$ & $4.0(0.8)$ & $4.0(1.3)^{\mathrm{c}, \mathrm{d}}$ & $4.7(1.4)$ & $4.9(1.1)$ \\
\hline $\mathrm{AT}(\mathrm{kg})$ & $11.5(9.3)$ & $4.4(0.8)^{\mathrm{c}, \mathrm{d}}$ & $7.5(3.8)^{\mathrm{c}, \mathrm{d}}$ & $20.4(7.0)^{\mathrm{d}}$ & $36.6(9.3)$ \\
\hline $\operatorname{SMT}(k g)$ & $19.6(6.5)$ & $18.8(4.0)$ & $19.0(6.3)$ & $21.2(6.8)$ & $22.8(6.6)$ \\
\hline RT (kg) & $16.4(4.3)$ & $18.3(3.0)$ & $16.8(4.2)^{\mathrm{d}}$ & $15.3(4.7)$ & $13.5(3.4)$ \\
\hline \multicolumn{6}{|c|}{ Estimated $R E E_{D X A}$} \\
\hline $\mathrm{REE}_{\mathrm{BT}}(\mathrm{kcal} /$ day $)$ & $9.5(3.1)$ & $9.2(1.8)$ & $9.1(3.0)^{\mathrm{c}, \mathrm{d}}$ & $10.7(3.3)$ & $11.3(2.5)$ \\
\hline $\mathrm{REE}_{\mathrm{AT}}(\mathrm{kcal} /$ day $)$ & $51.9(41.9)$ & $19.8(3.5)^{\mathrm{c}, \mathrm{d}}$ & $33.8(17.3)^{\mathrm{c}, \mathrm{d}}$ & $91.7(31.7)^{\mathrm{d}}$ & $164.6(41.8)$ \\
\hline $\mathrm{REE}_{\mathrm{SMT}}(\mathrm{kcal} /$ day $)$ & $255.5(84.1)$ & $245.0(51.2)$ & $247.5(82.2)$ & $275.1(88.5)$ & $295.8(85.3)$ \\
\hline $\mathrm{REE}_{\mathrm{RT}}$ (kcal/day) & 883.5 (232.9) & $985.8(161.4)$ & $907.1(225.2)^{\mathrm{d}}$ & $828.2(255.8)$ & $727.4(182.9)$ \\
\hline
\end{tabular}

DXA: dual energy X-ray absorptiometry; REE: resting energy expenditure; REE ${ }_{\mathrm{DXA}}$ : resting energy expenditure given by DXA; BT: bone tissue; AT: adipose tissue; SMT: skeletal muscle tissue; RT: residual tissue; $\mathrm{REE}_{\mathrm{BT}}$ resting energy expenditure of bone tissue; $\mathrm{REE}_{\mathrm{RT}}$ : resting energy expenditure of residual tissue; $\mathrm{REE}_{\mathrm{AT}}$ : resting energy expenditure of adipose tissue; $\mathrm{REE}_{\mathrm{SMT}}$ : resting energy expenditure of skeletal muscle tissue;

a, b, c, differences among nutritional groups $(p<0.05)$.

When the differences of BC components were compared, the statistical indicators ( $F$ and sig.) that resulted from ANOVA were the same for all the variables of body composition - organ-tissue level and $\mathrm{REE}_{\mathrm{DXA}}$. The ANOVA did not reveal any significant differences $\left(F_{(3,274)}=0.071, p=0.976\right)$ when the total $\mathrm{REE}_{\mathrm{DXA}}$ were compared among groups. When, however, the specific expenditures of each component were compared, differences among groups were found for all components: BT and $\mathrm{REE}_{\mathrm{BT}}$ $\left(F_{(3,274)}=5.794, p=0.001\right), \mathrm{AT}$ and $\mathrm{REE}_{\mathrm{AT}}\left(F_{(3,274)}=229.543, p\right.$ $<0.001), \mathrm{SMT}$ and $\mathrm{REE}_{\mathrm{SMT}}\left(F_{(3,274)}=2.820, p=0.039\right)$, and RT and $\operatorname{REE}_{\mathrm{RT}}\left(F_{(3,274)}=4.438, p=0.005\right)$.

The post hoc test revealed the groups in which differences concerning mass and REE occurred. Differences concerning the bone component $(p<0.05)$ occurred between NW-OW and between NW-OB, while differences regarding the adipose component $(p<0.001)$ were found among all groups, except between UW-NW $(p=1.000)$. In the visceral system and organs the differences $(p=0.022)$ occurred between NW-OB.

An estimate of total $\mathrm{REE}_{\mathrm{DXA}}$ normally represented by conventional methods ${ }^{21,28-30}$ does not show the estimate of the specific expenditure of each component. When, however, fractioning of $\mathrm{REE}_{\mathrm{DXA}}$ is specific for each component, differences concerning relative REE among groups, classified according to nutritional status, are apparent (Figure 1). 
Figure 1 . Total daily values (kcal/day) and relative (\%) estimated resting energy expenditure based on DXA among boys classified according to nutritional status.

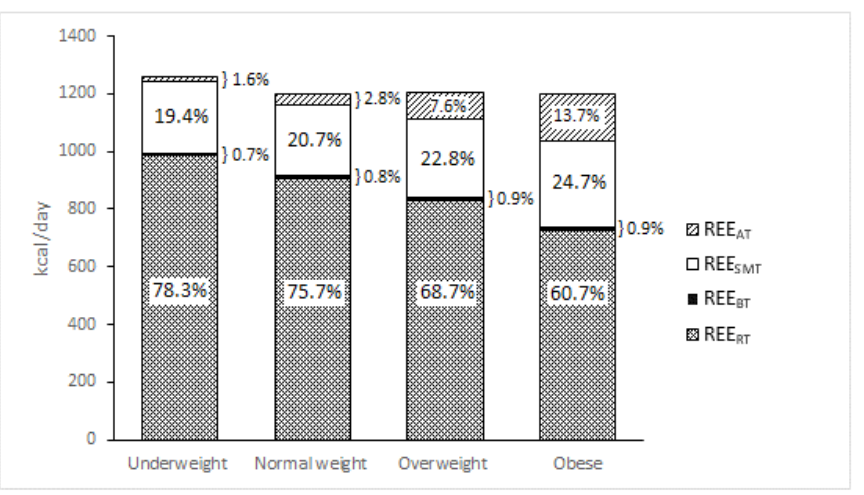

Note: REE: resting energy expenditure; AT: adipose tissue; SMT: skeletal muscle tissue; BT: bone tissue; RT: residual tissue.

The total daily $\mathrm{REE}_{\mathrm{DXA}}$ (kcal/day) presented an inverse relationship with body volumes represented in each nutritional status group. The greatest differences are perceived in the relative increase of $\mathrm{REE}_{\mathrm{AT}}$, from $1.6 \%$ to $13.7 \%$. The $\mathrm{REE}_{\mathrm{RT}}$ represents relatively greater participation in the daily total, inverse to body size (from $78.3 \%$ to $60.7 \%$ ). Body dimensions seem to play a smaller role in $\mathrm{REE}_{\mathrm{SMT}}$ and $\mathrm{REE}_{\mathrm{BT}}$, the values of which remained relatively similar among groups.

\section{Discussion}

The results concerning the total or specific $\mathrm{REE}_{\mathrm{DXA}}$ for each component reveal that REE varies according to one's nutritional status, with different and specific metabolic rates. It shows there is a clear advantage in identifying interpersonal differences in terms of energy metabolism, which is not always evident when traditional models are used ${ }^{20,28-30}$.

Beginning in the last century, efforts have been made to improve understanding regarding the relationship existing between energetic metabolism and the $\mathrm{BC}$ components ${ }^{8}$. With advancements achieved by studies addressing this topic ${ }^{3,9,12,31}$ and the availability of more accurate imaging methods (i.e., computed tomography, magnetic resonance and DXA), a new perspective that considers the specificity of REE for each component has emerged. Due to the high operational cost of magnetic resonance and computed tomography, as well as the risks associated with using contrasts and the high radiation emission rates, the use of imaging methods remain restricted to the scientific community. Hence, DXA emerges as a practical and accessible alternative to predict REE at the organ-tissue level ${ }^{12}$. In the present study, we showed the possibility of using DXA to estimate REE in children and adolescents.

In regard to nutritional status as determined by BMI, most boys presented weight appropriate to their age, though a considerable percentage (24.8\%) of individuals were classified as overweight or obese. These results portray the Brazilian context in which the prevalence of being overweight and obese among male adolescents is $21.7 \%$ and $5.9 \%$, respectively ${ }^{32}$.

The possibility of mapping metabolic REE for each component enables differentiating expenditure at high and low metabolic rates. ALST given by DXA, i.e., which characterizes Skeletal Muscle Tissue ${ }^{25}$, represents only $20 \%$ to $30 \%$ of REE in adults, even though it constitutes $40 \%$ to $50 \%$ of total body weight ${ }^{3,9}$; this reveals a low specific metabolic rate $(13 \mathrm{kcal} / \mathrm{kg} /$ day) in the total estimated REE. The LST of the trunk and head, on the other hand, which includes organs and tissues, represents only $6 \%$ of the total body weight but expresses a relatively high metabolic rate (200 to $440 \mathrm{kcal} / \mathrm{kg} / \mathrm{day})^{3}$, which denotes $60 \%$ to $70 \%$ of total daily REE.

The relatively higher AT presented by the OB group (Figure 1) accounted for $13.7 \%$ of the total $\mathrm{REE}_{\mathrm{DXA}}$. This increase in the REE variation is expected in populations with greater proportions of $\mathrm{fat}^{33}$. Nonetheless, comparisons based on multiple regression analysis indicate that the REE of FFM can be 3 to 7 times greater than that of AT REE ${ }^{34}$; a similar proportion was found in this study's results. This type of analysis, considering subgroups with different adiposity levels, has shown that the REE variance explained by FFM and AT presents approximately $80 \%$ of the variation in greater adiposity levels and values below $59 \%$ in overweight individuals; i.e., the contribution of AT to the variance of REE increases with higher adiposity levels ${ }^{35}$. For this reason, FFM is the main determinant of REE and both AT and FFM add variance to REE in different adiposity levels $\mathrm{s}^{34}$.

The $\mathrm{REE}_{\mathrm{AT}}$ of the OB group ( $\left.164.6 \mathrm{kcal} / \mathrm{day}\right)$, presented in Table 2, was $55.7 \%$ greater than that of the OW group; $80.6 \%$ greater than the NW group; and $89.5 \%$ greater than the AT of the UW group. Even presenting a low metabolic rate ${ }^{36}$, AT may be an important factor in REE because the gaini or loss of AT leads to compensatory adjustments in $\mathrm{REE}^{37}$ and adipose tissue may be coupled with energy homeostasis by "adiposity markers", such as leptin and insulin, which act on the central nervous system and influence behavioral and autonomic outputs for energy restoration or fat balance ${ }^{38}$. These factors contribute to an increase REE in obesity, partially explaining the greater total $\mathrm{REE}_{\mathrm{DXA}}$ in the OB group addressed in this study.

The relationship of REE in FFM varies according to body mass ${ }^{9}$, hence, individuals with lower mass and FFM present a greater REE/FFM relationship than individuals with a greater body mass 5 . A similar example is observed in all mammals, where small animals have greater proportions of FFM with high metabolic rates and lower amounts of low metabolic rate components; hence, REE in FFM decreases with an increase in $\mathrm{FFM}^{3}$. This phenomenon was seen in the inverse relationship between REE and the extent that the body size of nutritional groups increased (Table 2). This fact may be explained by the composition of FFM, as the tendency of greater $\mathrm{REE}_{\mathrm{RT}}$ in the UW group and lower $\mathrm{REE}_{\mathrm{RT}}$ in the OB group, as confirmed in our results.

Therefore, analysis of $\mathrm{BC}$, which considers the functional factors of body components, improves knowledge concerning the individual REE variance ${ }^{39}, 40$. The models that consider only two compartments, FM and FFM for instance, are insufficient to explain these variations because they do not 
consider individual differences and the specificity of FFM, a heterogeneous component ${ }^{3,4}$. In this sense, a more detailed analysis of body components adds a more sophisticated perspective of diseases, metabolism and nutritional status ${ }^{34}$, enabling nutritional interventions and the prescription of more effective exercise programs. The differences of organs and tissues contribute to explaining the different REE found among underweight, overweight and obese adults ${ }^{11}$, a behavior also observed in terms of the $\mathrm{Kg}$ of each component of $\mathrm{BC}$ - organtissue level (Table 2).

As this is the first study to present an REE fractioned based on DXA among children and adolescents, there are some limitations. The equations used to estimate REE are not specific for children and adolescents, so we adapted the adult model. Additionally, these equations do not consider growth energy expenditure for different ages ${ }^{20}$. We did not investigate the effects of maturation. That was not the purpose. This study's results, however, present coherent regularity, because the REE coincide with the body mass $(\mathrm{kg})$ of each component, as it is derived from this estimate.

Further studies addressing the use of methods that quantify the metabolic rate of organs and tissues in pediatric populations are needed to shed light on the variations of REE among children and adolescents. The energy demand of the organs or the effect of maturation on REE, considering the somatic variation of body components, could also be investigated.

\section{Conclusion}

The predictive models presented herein to estimate total REE, and that of organ-tissue components, represent a new approach to monitoring the energy metabolism of children and adolescents. The total $\mathrm{REE}_{\mathrm{DXA}}$ failed to confirm differences among nutritional groups, suggesting that estimated total REE presents low sensibility to distinguish interpersonal differences. On the other hand, the specific expenditure per component presented here, provides new insights to understanding the mechanism of energy metabolism, broadening understanding of differences in regard to the mass of metabolically active tissue. Even though this is the first study to estimate REE by DXA of children and adolescents, it introduces an applicable tool both for prescribing exercise programs and administering specific diets for pediatric populations. It signifies an important advancement in the analysis of REE of the tissue of interest, expressing the real magnitude of heat-producing body components.

\section{References}

1. Conde WL, Monteiro CA. Valores críticos do índice de massa corporal para classificação do estado nutricional de crianças e adolescentes brasileiros. J Pediatr . 2006;82:266-72.

2. Heymsfield SB, Thomas D, Bosy-Westphal A, Shen W, Peterson $\mathrm{CM}$, Muller MJ. Evolving concepts on adjusting human resting energy expenditure measurements for body size. Obesity reviews: an official journal of the International Association for the Study of Obesity. Int J Obes. 2012;13(11):1001-14.

3. Elia M. Organ and Tissue Contribution to Metabolic Rate. In: Tucker JMKeHN, editor. Energy Metabolism: Tissue Determinants and Cellular Corollaries. New York: Raven Press, Ltd.; 1992. p. 61 a 79.

4. Muller MJ, Bosy-Westphal A, Kutzner D, Heller M. Metabolically active components of fat-free mass and resting energy expenditure in humans: recent lessons from imaging technologies. Obesity reviews : an official journal of the International Association for the Study of Obesity. Int J Obes. 2002;3(2):113-22.

5. Ravussin E, Bogardus C. Relationship of genetics, age, and physical fitness to daily energy expenditure and fuel utilization. Am J Clin Nutr. 1989;49(5 Suppl):968-75.

6. Usui C, Taguchi M, Ishikawa-Takata K, Higuchi M. The Validity of Body Composition Measurement Using Dual Energy X-Ray Absorptiometry for Estimating Resting Energy Expenditure. DEXA. 2011:45.

7. Elia M. The inter-organ flux of substrates in fed and fasted man, as indicated by arterio-venous balance studies. Nutr Res Rev. 1991;4(1):3-31.

8. Wang Z, Heshka S, Zhang K, Boozer CN, Heymsfield SB. Resting energy expenditure: systematic organization and critique of prediction methods. Obes Res. 2001;9(5):331-6.

9. Gallagher D, Belmonte D, Deurenberg P, Wang Z, Krasnow N, Pi-Sunyer FX, et al. Organ-tissue mass measurement allows modeling of REE and metabolically active tissue mass. Am J Physiol-Endocrinol Metab 275(2):E249-E258.

10. Wang Z, Heshka S, Gallagher D, Boozer CN, Kotler DP, Heymsfield SB. Resting energy expenditure-fat-free mass relationship: new insights provided by body composition modeling. Am J Physiol Endocrinol Metab . 2000;279(3):E539-45.

11. Bosy-Westphal A, Reinecke U, Schlorke T, Illner K, Kutzner D, Heller M, et al. Effect of organ and tissue masses on resting energy expenditure in underweight, normal weight and obese adults. Int J Obes Related Metabol Disord. 2004;28(1):72-9.

12. Hayes M, Chustek M, Wang Z, Gallagher D, Heshka S, Spungen A, et al. DXA: Potential for Creating a Metabolic Map of OrganTissue Resting Energy Expenditure Components. Obes. Res. 2002;10(10):969-77.

13. Wang ZM, Pierson RN, Jr., Heymsfield SB. The five-level model: a new approach to organizing body-composition research. Am J Clin Nutr. 1992;56(1):19-28.

14. Borges GA, Machado DRL. Análise da maturação. In: Fonseca PHSd, editor. Promoção e avaliação da atividade física em jovens brasileiros. $1^{\circ}$ edição. São Paulo: Phorte; 2012. p. 121-51.

15. Wang H, Chen YE, Eitzman DT. Imaging body fat: techniques and cardiometabolic implications. Arterioscler Thromb Vasc Biol. 2014;34(10):2217-23.

16. Bosy-Westphal A, Braun W, Schautz B, Muller MJ. Issues in characterizing resting energy expenditure in obesity and after weight loss. Front Physiol. 2013;4:47.

17. Saúde WHO. FAO. Human energy requirements: report of joint FAO/WHO/ONU expert consultation. Itália. 2001.

18. Wang Z, Heymsfield SB, Ying Z, Pierson RN, Jr., Gallagher D, Gidwani S. A cellular level approach to predicting resting energy 
expenditure: Evaluation of applicability in adolescents. American journal of human biology : the official journal of the Human Biology Council. 2010;22(4):476-83.

19. Weber DR, Leonard MB, Zemel BS. Body composition analysis in the pediatric population. Pediatric endocrinology reviews : PER. 2012;10(1):130-9.

20. Heird WC. Nutritional requirements during infancy. In: Shils ME, Olson JA, Shike M, Ross AC, editors. Modern nutrition in health and disease. Baltimore: Williams \& Wilkins; 1999. p. 839-55.

21. Dubois D, Dubois EF. Clinical calorimetry: Tenth paper a formula to estimate the approximate surface area if height and weight be known. Arch Intern Med. 1916;XVII(6_2):863-71.

22. Machado D, Oikawa S, Barbanti V. The multicomponent anthropometric model for assessing body composition in a male pediatric population: a simultaneous prediction of fat mass, bone mineral content, and lean soft tissue. J Obes. 2013;2013:428135.

23. Tanner JM. Growth at adolescence. 2nd ed. Oxford: Blackwell Scientific; 1962.

24. Lohman TG, Roche AF, Martorell R. Anthropometric standardization reference manual: Human Kinetics Books; 1988.

25. Kim J, Wang Z, Heymsfield SB, Baumgartner RN, Gallagher D. Total-body skeletal muscle mass: estimation by a new dual-energy X-ray absorptiometry method. Am J Clin Nutr. 2002;76(2):378-83.

26. Kim J, Shen W, Gallagher D, Jones A, Jr., Wang Z, Wang J, et al. Total-body skeletal muscle mass: estimation by dual-energy X-ray absorptiometry in children and adolescents. Am J Clin Nutr. 2006;84(5):1014-20.

27. Bayer LM, Bayley L. Growth diagnosis. Chicago: University of Chicago Press; 1959.

28. FAO/WHO/UNU. Energy and protein requirements. Report of a joint FAO/WHO/UNU Expert Consultation. World Health Organization technical report series. 1985;724:1-206.

29. Harris JA, Benedict FG. A Biometric Study of Human Basal Metabolism. Proceedings of the National Academy of Sciences of the United States of America. 1918;4(12):370-3.

30. Schofield WN. Predicting basal metabolic rate, new standards and review of previous work. Hum Nutr Clin Nutr. 1985;39 Suppl $1: 5-41$.

31. Sardinha LB, \& Teixeira, P. J. . Measuring adiposity and fat distribution in relation to health. In: Heymsfield SB, Lohman, T. G., Wang, Z. M., Going, S. B., editor. Human Body Composition: Champaign, OL: Human Kinetics; 2005.

32. Brasil. Pesquisa de orçamentos familiares 2008-2009. Contagem Populacional. In: Ministério do planejamento oeg, editor. Brasília: IBGE; 2010.

33. Nelson KM, Weinsier RL, Long CL, Schutz Y. Prediction of resting energy expenditure from fat-free mass and fat mass. Am J Clin Nutr. 1992;56(5):848-56.

34. Müller MJ, Bosy-Westphal A, Heller M. 'Functional' body composition: differentiating between benign and non-benign obesity. F1000 Biology Reports. 2009;1.

35. Bosy-Westphal A, Muller MJ, Boschmann M, Klaus S, Kreymann G, Luhrmann PM, et al. Grade of adiposity affects the impact of fat mass on resting energy expenditure in women. Br J Nutr. 2009;101(4):474-7.
36. Kaiyala KJ, Morton GJ, Leroux BG, Ogimoto K, Wisse B, Schwartz MW. Identification of body fat mass as a major determinant of metabolic rate in mice. Diabetes. 2010;59(7):1657-66.

37. Dulloo AG, Jacquet J. Adaptive reduction in basal metabolic rate in response to food deprivation in humans: a role for feedback signals from fat stores. Am J Clin Nutr. 1998;68(3):599-606.

38. Morton GJ, Cummings DE, Baskin DG, Barsh GS, Schwartz MW. Central nervous system control of food intake and body weight. Nature. 2006;443(7109):289-95.

39. Gallagher D, Albu J, He Q, Heshka S, Boxt L, Krasnow N, et al. Small organs with a high metabolic rate explain lower resting energy expenditure in African American than in white adults. Am J Clin Nutr. 2006;83(5):1062-7.

40. Muller MJ, Bosy-Westphal A, Later W, Haas V, Heller M. Functional body composition: insights into the regulation of energy metabolism and some clinical applications. Eur J Clin Nutr. 2009;63(9):1045-56.

41. Heymsfield SB, Gallagher D, Kotler DP, Wang Z, Allison DB, Heshka S. Body-size dependence of resting energy expenditure can be attributed to nonenergetic homogeneity of fat-free mass. Am J Physiol Endocrinol Metab. 2002;282(1):E132-8.

42. Ballor DL. Exercise Training and Body Composition Changes. In: Lohman TG, editor. Human Body Composition. Champaign: Human Kinetics. 1996. p. 287-304.

43. Snyder WS, Cook MJ, Nasset ES, Karhausen LR, Howells GP, Tipton IH. Report of the task group on reference man. International Commission on radiological protection $\mathrm{n}^{\mathrm{o}} 23$ : Oxford: Pergamon Press, 1975.

\section{Acknowledgements}

Support: CAPES

\section{Corresponding author}

*Ana Claudia Rossini Venturini

Graduate Program - University of São Paulo, School of Physical Education and Sport of Ribeirao Preto (EEFERP-USP).

Email: anacrv@usp.br

Manuscript received on August 16, 2017

Manuscript accepted on August 31, 2017

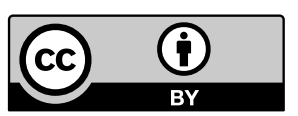

Motriz. The Journal of Physical Education. UNESP. Rio Claro, SP, Brazil - eISSN: 1980-6574 - under a license Creative Commons - Version 3.0 